\title{
THE EFFECT OF HATHA YOGA ON PSYCHOEMOTIONAL CHARACTERISTICS IN HEALTHY SUBJECTS
}

\author{
Eglė Kasparavičiūtė ${ }^{1}$, Laimonas Šiupšinskas ${ }^{1,2}$, Jonas Poderys ${ }^{1,2}$ \\ Lithuanian University of Health Sciences ${ }^{1}$, Kaunas, Lithuania \\ Lithuanian Sports University², Kaunas, Lithuania
}

\begin{abstract}
Research background and hypothesis. There is a lack of evidence-based information about the effect of hatha yoga on psychoemotional characteristics of healthy people in recent scientific papers. Most of the researchers use self-reported methods to evaluate psychoemotional factors. We used objective method to find out what kind of effect could be found on psychoemotional characteristics of yoga practitioners. Hypothesis: hatha yoga practice has different effect on psychoemotional characteristics in beginners and advanced yoga practitioners.

Research aim was to evaluate the effect of hatha yoga on psychomotoric tone, extra-introversity, aggression, emotional lability and anxiety in healthy subjects.

Research methods. 40 healthy persons with no reported diseases participated in the research. Participants were divided into two groups: beginners (practicing yoga for not more than one year, $\mathrm{n}=22$ ) and advanced (practicing yoga for at least two years, $\mathrm{n}=18$ ) yoga practitioners. Psychoemotional characteristics: inborn and present psychomotoric tone, extra-introversity, aggression, emotional lability and anxiety were measured using the Myokinetic Psyhodiagnosis of D. Emilio Mira (Simon, 1943) test. The research data was compared with standard limits and between the beginners and advanced yoga practitioners groups.

Research results. Hatha yoga had general effect on psychoemotional status in the beginners and advanced yoga practitioners. Psychomotoric tone increased and emotional lability decreased in both groups $(\mathrm{p}<0.05)$. Psychomotoric tone, extra-introversity and emotional lability were within the standard limits. Anxiety and aggression were lower in both groups in 6-months period. Aggression and emotional lability in the beginners' group was lower compared to those in the advanced yoga group $(\mathrm{p}<0.05)$.

Discussion and conclusions. Almost all psychoemotional characteristics were within the standard limits in both groups of yoga practitioners. The bigger effect of hatha yoga was found in the yoga beginners' group. The evidencebased information in scientific literature about the effect of yoga on psychoemotional characteristics with objective measures is still missing.
\end{abstract}

Keywords: hatha yoga, psychomotoric test, psychoemotional characteristics.

\section{INTRODUCTION}

$\mathrm{N}$ umerous of articles about yoga can be found in popular literature in recent years. The popularity of yoga is increasing. Alternative lifestyles publications, mainstream magazines have featured numerous articles about yoga's effects on the mind, body and spirit. Current outpouring of publicity reflects that over the past few decades interest in this field has grown up. Popular periodicals and books make many assumptions about the benefits of yoga, crediting the practice with improving various aspects of physical health and psychological states (Lee, 2004)

Researchers have conducted clinical studies to substantiate the beneficial effects of yoga in healthy and ill subjects. Studies have shown that yoga practice can lead to improvements in handgrip strength, muscular endurance and flexibility. In 
addition, increases in forced vital capacity, forced expiratory volume in 1 second and other spirometer values have also been observed (Mark, Tran, 2001).

Majority of the studies are putting focus on the relationship between yoga and physical fitness. Effect of yoga on healthy person's psychoemotional characteristics has rarely been evaluated. In most yoga studies psychoemotional factors are assessed using self-reported methods - questionnaires. Psychomotoric test gives a great opportunity to reveal natural psychological health status and to differentiate present and inborn psychoemotional characteristics. This method is an objective measure originally presented in 1996 by V. Jasiūnas and S. Bagočiūnas.

Research aim was to evaluate the effect of hatha yoga practice on healthy subjects' psychomotoric tone, extra-introversity, aggression, emotional lability and anxiety.

The participants of the study were healthy subjects with no signs or reported diseases and who were regularly practicing hatha yoga.

\section{RESEARCH METHODS}

The study was carried out in Lithuania, "Kauno jogos studija", in 2011-2013. We examined 40 healthy persons who were regularly practicing hatha yoga with the same yoga instructor. Participants were divided into two groups: beginners (regularly practicing yoga for not more than one year, 22 persons) and advanced (regularly practicing yoga for at least two years, 18 persons) yoga practitioners (Table 1). The measurements of yoga practitioners were accomplished before the start of yoga practice and again after three and six months of yoga practice (Figure 1). Yoga training sessions (two times per week) included postures and breathing techniques.

Psychoemotional characteristics were measured using the Myokinetic Psyhodiagnosis of D. Emilio Mira (Simon, 1943) test (Jasiūnas, Bagočiūnas, 1996; Tous, Viadé y Rubén Muiños, 2007). This test allows getting objective and visual information about the rate level of psychoemotional state (Jasiūnas, Bagočiūnas, 1996). We assessed five inborn and present psychoemotional characteristics: psychomotoric tone, extraintroversity, aggression, emotional lability and anxiety. The test was performed by asking the subject to draw 2 horizontal and 4 vertical lines 4 centimeters length as close as possible to the printed lines. At the beginning of the test the subject was allowed to see the lines, but later the eyes were closed and the subject continued the drawing. The idea of the test was to draw the lines as accurate as possible. The length, amplitude and deviation were measured and analyzed. Results of nondominant arm present the inborn characteristics (temperament) that are usually conservative and stable. Results of dominant arm show the present condition of psychoemotional status.

\begin{tabular}{|l|c|c|c|c|c|}
\hline \multicolumn{1}{|c|}{ Group } & $\mathbf{n}$ & Age, years & Body height, cm & Body weight, kg & $\begin{array}{c}\text { Practicing yoga, } \\
\text { months }\end{array}$ \\
\hline Beginners & 22 & $26.55 \pm 2$ & $161.58 \pm 7.73$ & $60.95 \pm 1.64$ & $4.32 \pm 0.57$ \\
\hline Advanced & 18 & $32.28 \pm 22.02$ & $173.56 \pm 1.82$ & $64.44 \pm 2.65$ & $37.33 \pm 3.05$ \\
\hline Female & 28 & $28.75 \pm 1.77$ & $162.21 \pm 6.04$ & $58.93 \pm 1.38$ & $19.18 \pm 3.76$ \\
\hline Male & 12 & $30 \pm 2.8$ & $178.08 \pm 1.71$ & $70.75 \pm 2.62$ & $19.17 \pm 4.84$ \\
\hline All & 40 & $29.13 \pm 1.48$ & $166.97 \pm 4.39$ & $62.56 \pm 1.52$ & $19.18 \pm 2.97$ \\
\hline
\end{tabular}

Table 1. General characteristics of subjects in yoga groups (Mean \pm SEM)

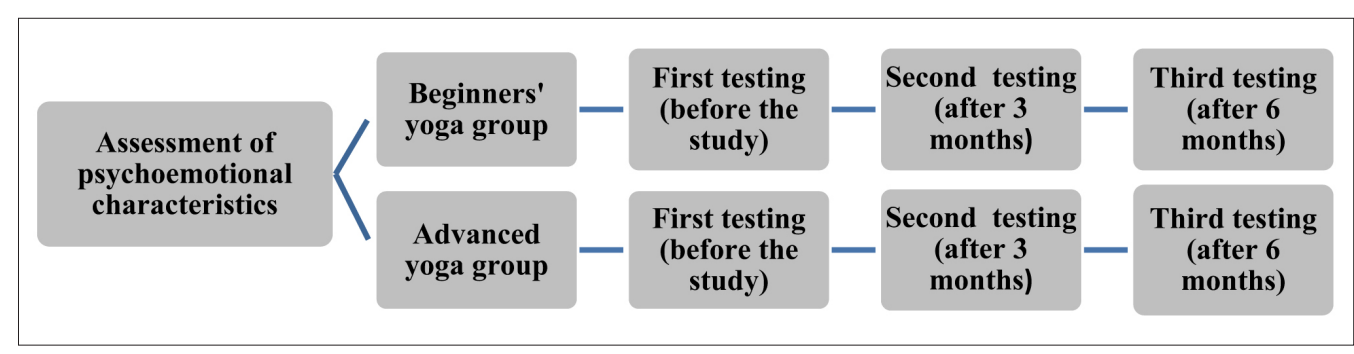

Figure 1. Scheme of the study 
Statistical analysis was performed using Microsoft Office Excel and IBM SPSS software packages. In order to identify the differences between two independent groups we used the Mann-Whitney U test, between three related groups - Friedman test. The results are represented as arithmetic mean \pm the standard error of the mean (SEM). Statistical significance was accepted when $\mathrm{p}<0.05$. Each measured and analyzed parameter in figures was presented comparing it with standard limits (45-55), revealed by Jasiūnas and Bagočūnas in 1996. The standard limits were estimated after measuring the number of athletes. The measurements were taken three times: at the beginning of the research, after 3 and 6 months of hatha yoga practice.

\section{RESEARCH RESULTS}

The significant improvement of inborn psychomotoric tone was observed in the beginners' yoga group after six months (from $51.27 \pm 1.64$ to $54.73 \pm 0.73$ ) of practice.

Present psychomotoric tone significantly increased $(p<0.05)$ in the period from three to six months of yoga in both groups. In advanced yoga practitioners' group after six months of practice psychomotoric tone increased compared with the results at the beginning of the study (Figure 2). There were no significant differences between the groups.

There were no statistically significant changes in inborn and present extra-introversity in any of the study groups $(p>0.05)$. In general, extra-introversity was within the standard limits (Figure 3).
Figure 2. Present psychomotoric tone in the beginner and advanced yoga groups
Figure 3. Present extra-introversity in the beginner and advanced yoga groups
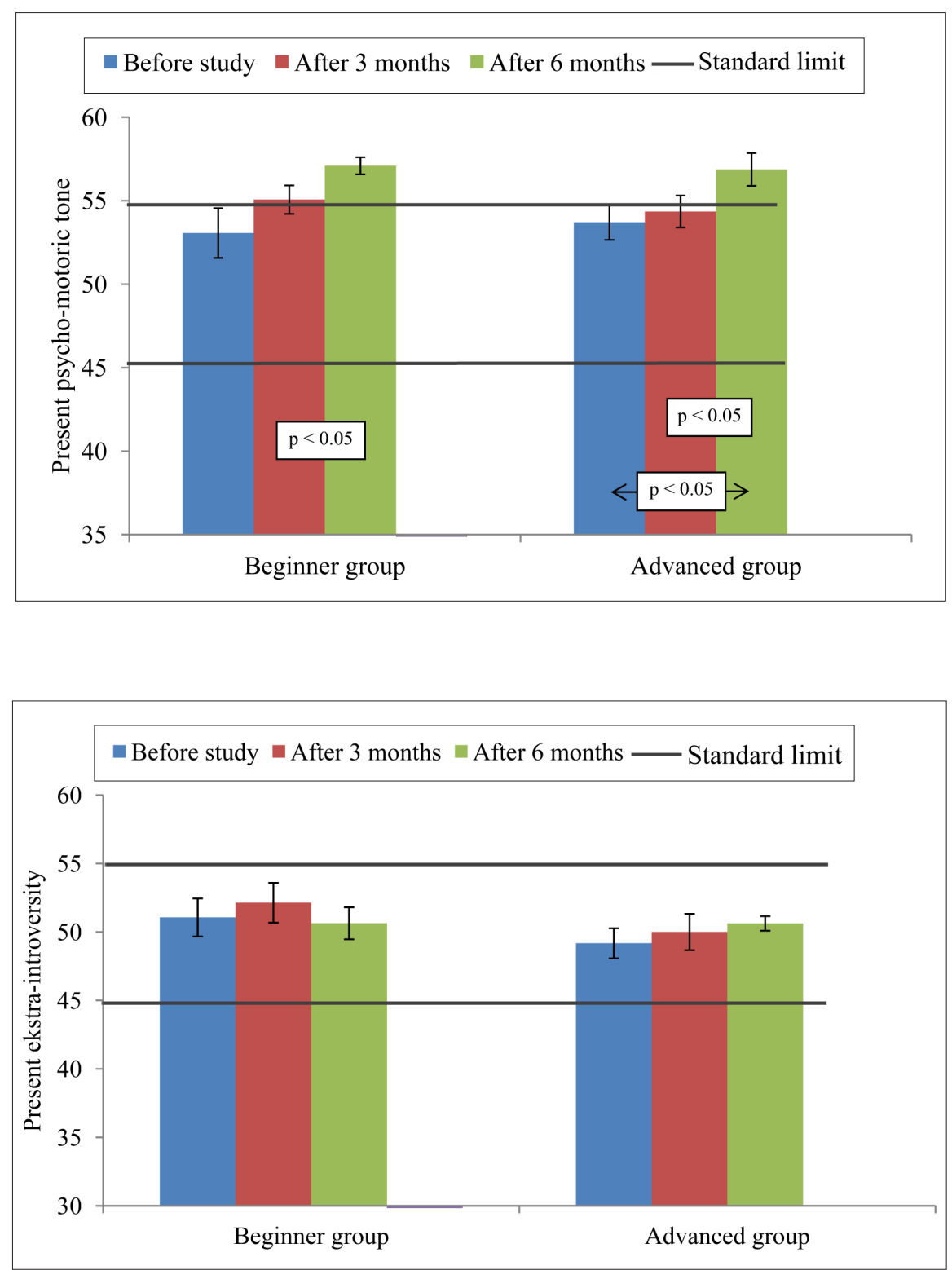
Advanced yoga practitioners had significantly higher $(\mathrm{p}<0.05)$ inborn aggression after three months and six months compared to the beginners. This parameter was lower than the standard limit in the beginner group and was within the standard limits in the advanced yoga group.

Changes of present aggression are presented in Figure 4. The lower present aggression was observed in the beginners' group compared to the advanced yoga practitioners after six months of hatha yoga. In both groups present aggression was lower than the standard limit.

In contrast, inborn emotional lability was at the same level and did not change in both groups. The inborn emotional lability was within the standard limits.

Present emotional lability gradually decreased $(p<0.05)$ in each measurement period. At the beginning and after 3 months of yoga this parameter was within the standard limits, after six months of yoga it was lower than the standard limit in the beginner group. Advanced yoga practitioners had higher $(\mathrm{p}<0.05)$ values of present emotional lability after three months and six months of yoga compared with the beginners (Figure 5).

There were no significant changes in inborn and present anxiety. In both groups the level of anxiety was within the standard limits (Figure 6).

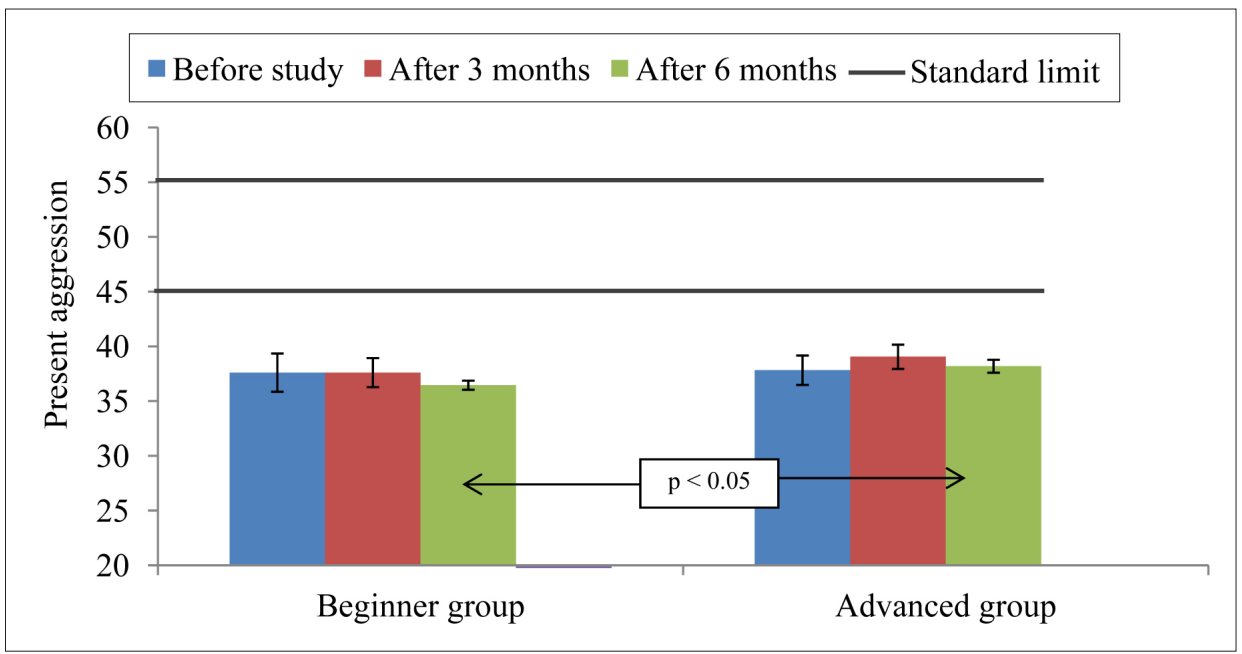

Figure 4. Present aggression in the beginner and advanced yoga groups

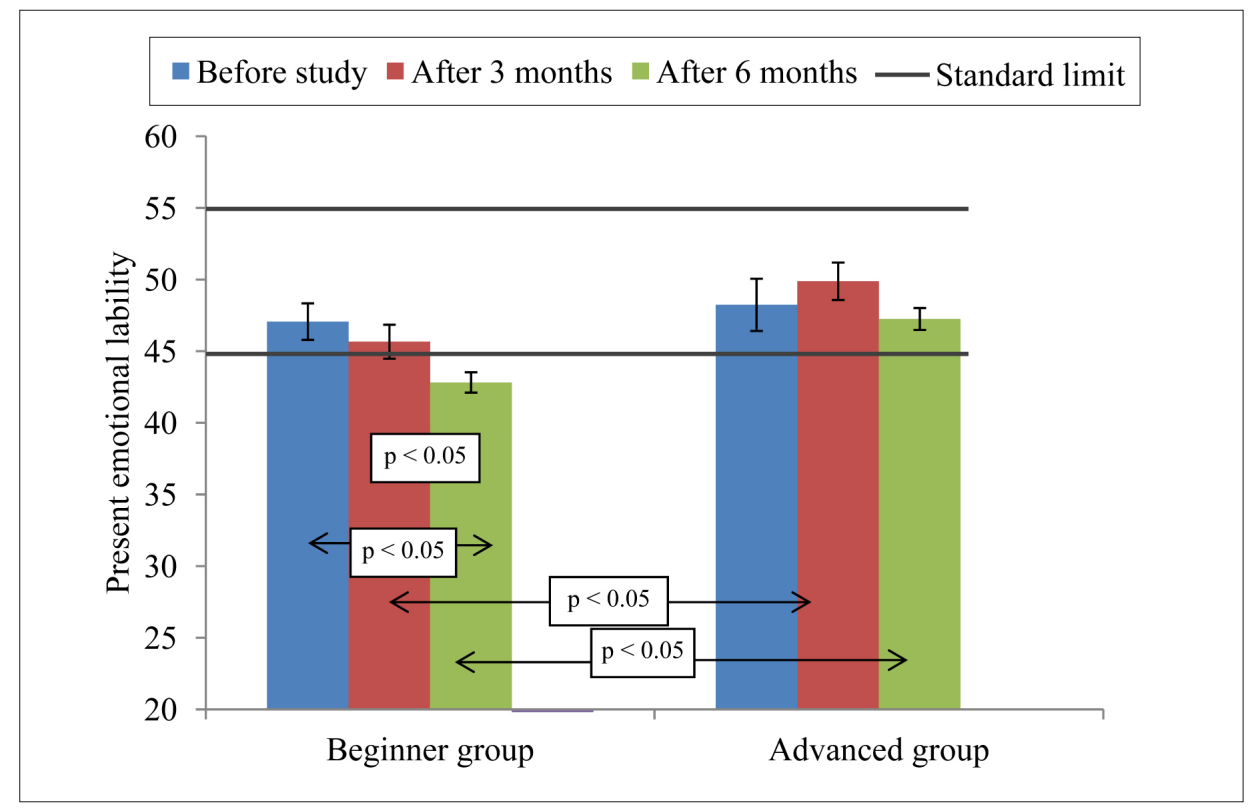


Figure 6. Present anxiety in the beginner and advanced yoga groups

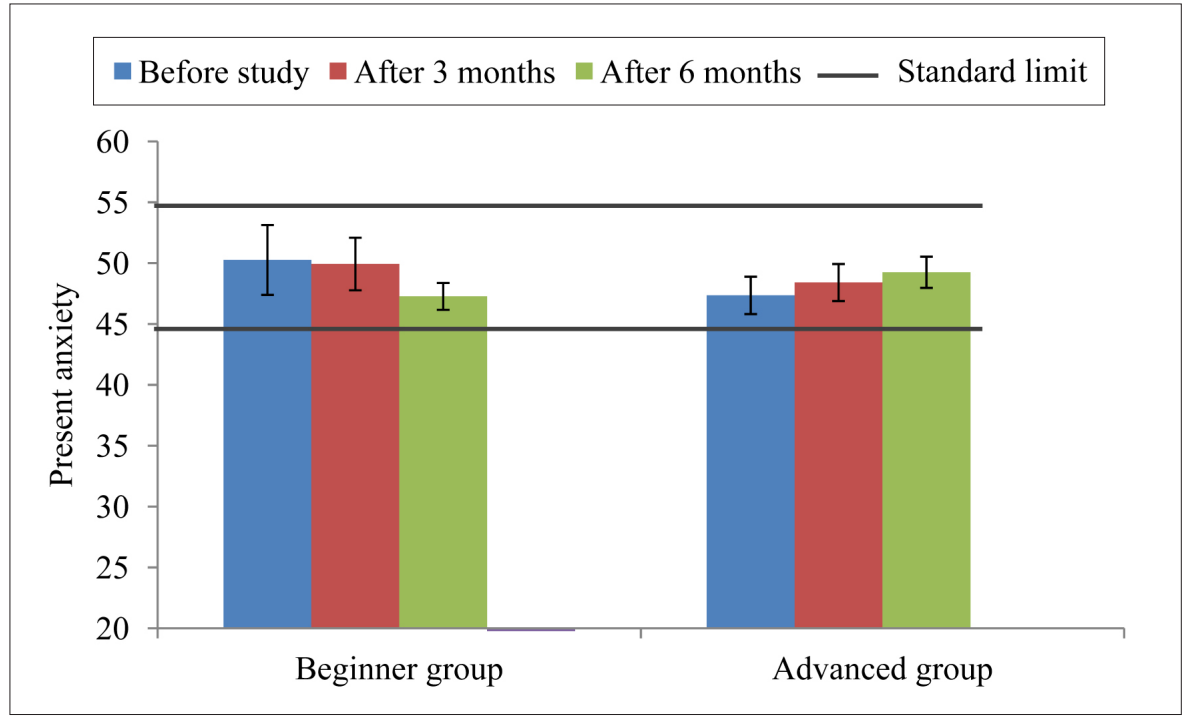

\section{DISCUSSION}

The practice of yoga having favorable effects on different body systems has been convincingly shown by various studies from time to time. The present study was undertaken to see the effect of yoga practice on the level of psychomotoric tone, extra-introversity, aggression, emotional lability and anxiety.

From the results of the present study it is evident that yoga practice has a positive effect on psychoemotional characteristics. Various studies have reported similar findings. However, there is a lack of scientific papers about the effect of yoga on psychoemotional qualities. Most of the researchers measure psychoemotional state using self-reported questionnaires.

In 1996 V. Jasiūnas and S. Bagočiūnas presented a tool to measure psychoemotional qualities applying psychomotoric (E. Mira y Lopez) test. They investigated athletes. We have not found any research which used this test to assess the effectiveness of yoga.

R. K. Yadav et al. (2012) established significant improvement in personality by increased scores for extraversion. However, D. Eliseev et al. (2012) stated that extravertion, intravertion had not changed after yoga sessions two times per week for two years. After six months of yoga practice we did not find any significant changes in inborn and present extraintroversity in any of the study groups.

There was no research found about the effect of yoga on psychomotoric tone.

D. Eliseev et al. (2012) examined the efficacy of hatha yoga intervention in female students. At the end of the study participants tended to increase in emotional lability. Our study proved that present emotional lability was reduced after three and six months of yoga in the beginner group $(\mathrm{p}<0.05)$.

S. Deshpande et al. (2008) evaluated the effect of yoga on the aggressiveness in normal healthy adults. Their study demonstrated that an eight-week, daily intervention of yoga decreased aggressiveness. In our research there were no significant changes in inborn and present aggressiveness. It could occur because the type of assessment tool used in that research study may not have been the most suitable one to bring out the subtle changes that may have occurred after the yoga practice.

It is known that yoga with its holistic approach uses several techniques to calm down the mind and reduce the anxiety state. R. Mehrotra et al. (2012) evaluated the effect of yoga on the anxiety score in young healthy individuals. They found statistically significant decrease in the anxiety score in females and males after three months of daily practice of yoga. N. Gupta (2006), R. K. Yadav et al. (2012) also estimated a significant reduction in state and trait anxiety after ten-day daily yoga sessions. C. Streeter et al. (2007) raised the hypothesis that yoga practice increased GABA levels in brain causing a decrease in anxiety. Reduction in anxiety also could be related to the reduction of sympathetic activity. In our study there were no significant changes $(p>0.05)$ in inborn and present anxiety after six months yoga practice. It could be affected by a small number of sessions during a week. 
Probable mechanism underlying changes in psychoemotional qualities following yoga practice was voluntary slow deep breathing (our subjects performed pranayamas) wich functionally resets the autonomic nervous system through stretchinduced inhibitory signals and hyperpolarization currents propagated via both neural and non-neural tissue which synchronizes neural elements in the heart, lungs, limbic system and cortex as explained by R. Jerath et al. (2006).

There has been no study which has compared beginners and advanced yoga practitioners in the content of psychoemotional characteristics. In our study the data was compared with the standard limit. Before yoga classes everybody demonstrated the accurate level of psychoemotional qualities, so persons could choose the type of yoga according to the test results.

\section{CONCLUSIONS AND PERSPECTIVES}

Hatha yoga had an effect on psychoemotional qualities in beginners' and advanced yoga groups. Psychomotoric tone increased and emotional lability decreased in both investigated groups $(p<0.05)$. The level of psychomotoric tone, extra-introversity and emotional lability was within the standard limits. The level of anxiety and aggression was lower than the standard limits in both groups after six-month of yoga. The level of aggression and emotional lability was lower in the beginners' group compared to the advanced yoga practitioners $(\mathrm{p}<0.05)$.

Acknowledgments. We are grateful to Vytis Zabulenas and his team for their contribution and support to run the regular yoga sessions at the "Kauno jogos studija".

\section{REFERENCES}

Deshpande, S., Nagendra, H. R. (2008). A randomized control trial of the effect of yoga on verbal aggressiveness in normal healthy volunteers. International Journal of Yoga, 1 (2), 76-82.

Eliseev, D., Venevtseva, Y. (2012). Effect of a Yoga Practice on State Anxiety and Autonomic Nervous System in University Students. Neurocard, September (p. 86). Belgrade: University Press TarguMures.

Gupta, N., Khera, S. (2006). Effect of yoga based lifestyle intervention on state and trait anxiety. Indian Journal Physiology and Pharmacology, 50 (1), 41-47.

Jasiūnas, V., Bagočiūnas, S. (1996). Sportininko psichologinès būsenos pagrindiniai rodikliai. Kardiovaskulinè sistema ir sportine veikla. Vilnius: LTOK. P. 23-25.

Jerath, R., Edry, J. W., Barnes, V. A., Jerath, V. (2006). Physiology of long pranayamic breathing: Neural respiratory elements may provide a mechanism that explains how slow deep breathing shifts the autonomic nervous system. Elsevier. Medical hypothesis, 67 (3), $566-571$.

Lee, G. W. (2004). The Subjective Well-being of Beginning vs. Advanced Hatha Yoga Practitioners. Honolulu: Hawai library. P. 2-5.
Mark, D., Tran, M. S. (2001). Effects of hatha yoga practice on the health-related aspects of physical fitness. Preventive Cardiology, 4 (4), 165-170.

Mehrotra, R., Phadke, A. V., Kharche, J. S., Pranita, A., Joshi, A. R. (2012). Effect of yoga on anxiety score and resting heart rate in young healthy individuals. National Journal of Integrated Research in Medicine, 3 (2), 142-146.

Simon, J. L. (1943). The myokinetic psyhodiagnosis of dr. Emilio Mira. American Journal of Psychiatry, 100, 334-341.

Streeter, C. C., Jensen, J. E., Perlmutter, R. M. et al. (2007). Yoga Asana sessions increase Brain GABA levels: A pilot study. The Journal of Alternative and Complementary Medicine, 13 (4), 419-426.

Tous, M. J., Viadé y Rubén Muiños, A. (2007). Validez estructural de los lineogramas del psicodiagnóstico mio kinético, revisado y digitalizado (PMK-RD). Psicothema, 19 (2), 350-356.

Yadav, R. K., Magan, D., Mehta, M., Mehta, N., Mahapatra, S. C. (2012). A short-term, comprehensive, yoga-based lifestyle intervention is efficacious in reducing anxiety, improving subjective well-being and personality. International Journal of Yoga, 5 (2), 134-139. 